\title{
La escritura ante el limite: lenguaje y narración en la operación historiográfica de Michel de Certeau
}

e

\section{The Writing in front of the Limit: Language and Narration in the Historiographical Operation of Michel de Certeau}

\author{
RAYIV DAVID TORRES \\ Universidad Nacional de Colombia \\ Colombia \\ DOI: 10.48102/hyg.vi56.334 \\ Correo: rd.torres42@uniandes.edu.co
}

Artículo recibido: 14/03/2020

Artículo aceptado: 25/05/2020

ABSTRACT

This work aims to highlight the genealogical nature of the writing of history as a common thread of the "economics of truth" in the West. In the light of Michel de Certeau, writing translates into a field of expansion and conquest in which not only would a mirror of the epistemologies of early modernity be drawn, but it has also been the stage for representation and production of a system of truth involving an experience alterity. This is the case, from the Sixteenth Century on, of Ethnology, Mystique, Psychoanalysis, and History: the "sciences of the other". In this order of ideas, Michel de Certeau's work will be the primary source for the theoretical analysis (multiple and at the limits) of a script that reproduces a permanent exercise of absence and that performs a duel for that which "is gone" and that could not be present anymore.

Keywords: Historiography, Alterity, Epistemology, Representation.

\section{RESUMEN}

Este trabajo se propone destacar el carácter genealógico de la escritura de la historia como un hilo conductor de la "economía de la verdad" en 
Occidente. A la luz de Michel de Certeau, la escritura se traduce en un campo de expansión y conquista en el que no sólo se dibujaría un espejo de las epistemologías de la modernidad temprana, sino que también ha sido el escenario de representación y producción de un sistema de verdad que involucra una experiencia de alteridad. Éste es el caso, a partir del siglo Xvi, de la etnología, la mística, el psicoanálisis y la historia: las "ciencias del otro". En este orden de ideas, la obra de Michel de Certeau será la fuente primaria para el análisis teórico (múltiple y en los límites) de una escritura que reproduce un ejercicio permanente de ausencia y que lleva a cabo un duelo por aquello que "ya no está" y que es de antemano irrestituible.

Palabras clave: historiografía, alteridad, epistemología, representación.

Que pensar quiera decir pasar, exceso hacia el otro, éxtasis mortal de la identidad, tal es aqui el sentido del procedimiento.

Michel de Certeau, "L'étrange secret. 'Manière d'écrire pascalienne'".

D obinson Crusoe camina siguiendo las huellas aún tangibles Re lo que ha partido para siempre, pero, al mismo tiempo, el navegante hace visibles continentes desaparecidos. Adecuando una nueva relación con su entorno, Crusoe representa la operación que nombra, acumula, coloniza y conquista; define con su propio límite el espacio para lo natural y lo extrańo, lo mismo y lo otro, lo propio y lo ajeno.

El náufrago en su isla desierta sería una figura emparentada con el historiador que compone sobre una página en blanco el "querer occidental" para la conquista de la oralidad. Ambos escriben por medio de la ausencia, por medio de los documentos que el historiador puede ver en la playa donde ya no está la presencia que los dejó, "y a través de un murmullo que nos permite oír, como venido de muy lejos, el sonido de la inmensidad desco- 
nocida que seduce y amenaza el saber" ${ }^{1}$ Esta amenaza comienza donde se pierde la inteligibilidad. "La inteligibilidad se establece con relación al 'otro', se desplaza (o 'progresa') al modificar lo que constituye su 'otro' -el salvaje, el pasado, el pueblo, el loco, el niño, el tercer mundo". ${ }^{2}$ En su forma más elemental, como se verá en las próximas páginas, escribir significa construir una frase recorriendo un lugar que se supone en blanco: la página. ${ }^{3}$

El texto de Daniel Defoe, Robinson Crusoe, es para Michel de Certeau la gran novela de la escritura. En ella se puede diagramar una triple definición de un lugar propio, un lugar de producción de un sistema de objetos organizado por un sujeto soberano y un lugar de transformación de un mundo natural en función de unas necesidades a todas luces circunstanciales y contingentes. Sin embargo, a la luz de Michel de Certeau, hay una oposición entre un eje estratégico y numerosas variables tácticas entre la escritura y la lectura. La escritura, por su parte, compete a la estrategia, a saber, a la práctica mítica de una modernidad occidental que busca asumir el dominio de un espacio propio, circunscrito y acumulativo; ${ }^{4}$ mientras que, en el caso de la lectura, en el otro extremo, se pone a prueba una especie de ardid que permite itinerarios múltiples, con recorridos sin cuadrícula ni división en el texto. La lectura es el origen de "las mil y un maneras de la creatividad táctica": "Lo que hay que poner en tela de juicio -dice de Certeau- no es, desgraciadamente, esta división del trabajo (demasiado real), pero la asimilación de la lectura a una pasividad. Efectivamente, leer significa peregrinar en un sistema impuesto". 5 Por otra parte, el juego de la escritura, uno insensato, como dijo Stéphane Mallarmé, se traduce en un puro despliegue de la estrategia, esto es, el carácter y la dimensión pragmática de toda forma de escritura.

${ }^{1}$ Michel de Certeau, La escritura de la historia, p. 17.

${ }^{2}$ Ibidem, p. 17.

${ }^{3}$ Ibidem, p. 19.

${ }^{4}$ François Dosse, Michel de Certeau. El caminante herido, p. 195.

${ }^{5}$ Michel de Certeau, La invención de lo cotidiano: artes de hacer, p. 245.

La escritura ante el límite: lenguaje y narración en la operación... / 28। 
Escribir designa, ante todo, una operación que se practica y no un sistema de sentido, de manera que el discurso no puede desasociarse de las prácticas, pero tampoco (de la formalidad) del texto. ${ }^{6}$ En este orden de ideas, a través de la escritura, en la historia, o, incluso la etnología, como se verá más adelante a propósito del viajero Jean de Léry, interesa destacar el papel organizador del lugar social que tomó la escritura a partir de la modernidad temprana entre los siglos XVI y XVII, es decir, el momento a partir del cual una sociedad es capaz de capitalizar y acumular escritura para pasar a ser un instrumento de difusión y de conquista. En este estudio se mostrará que este periodo es "el momento en el que la escritura transforma el espacio del otro en un campo de expansión para un sistema de producción”.

Si volvemos sobre el mito de Robinson Crusoe con el que hemos introducido este estudio, veremos que esta novela representa una ruptura moderna que se percibe como la tabula rasa de una sociedad que se instaura a partir de una página en blanco (salvaje). ${ }^{8}$ El relato de Defoe se compone de sus múltiples niveles a partir de unas cuantas escansiones que delimitan el campo de pensamiento de Certeau: los prolegómenos de una escritura capitalizante con "las primeras relaciones de viaje", luego la escritura que formaliza las razones de una práctica cada vez más apartada de un hacer, "reprimiendo los mitos fundadores transformados en objetos, y [en] el fin la vuelta de lo reprimido con lo que Freud hace a la

${ }^{6}$ Cabe anticipar al respecto que, al pensar una escritura indisociable de su práctica, Michel de Certeau toma una distancia no sólo con relación al "paradigma estructuralista” que postula el signo lingüístico como arbitrario, por cuanto no hay nada más allá de su "clausura textual", sino también con relación a la teoría del reflejo que "viene a ser como considerar la historiografía en una simple relación de exterioridad con respecto a la realidad", lo cual limita la investigación a adecuaciones o inadecuaciones entre el discurso y lo real. Cfr. Dosse, Michel de Certeau, op. cit., p. 265.

${ }^{7}$ Ibidem, p. 263.

${ }^{8}$ Cfr. Andrés Gabriel Freijomil, "El nuevo mundo como 'página en blanco'. Elementos para una historia de las representaciones de América Latina en la obra de Michel de Certeau”. 
historia", y, por último, una escritura que siempre tuvo como horizonte, al caminar sin cesar, la figura alterada por el otro. ${ }^{10}$

A continuación, nos serviremos del estudio de Michel de Certeau sobre Jean de Léry, quien encarna con su expedición a Brasil a mediados del siglo xvi aquello que Claude Lévi-Strauss concebía como el "breviario del etnólogo" (como bien podrían serlo también los jesuitas Pierre Favre, Francisco Javier, o Jean de Labadie). En ese estudio, titulado Etno-grafía. La oralidad o el espacio del otro: Léry, posteriormente consignado en la La escritura de la historia, ${ }^{11}$ Michel de Certeau ubica los indicios del nacimiento de la etnología, cuyas características, como lo ha señalado el profesor Alfonso Mendiola, son compartidas con las de cualquier empresa científica moderna desde hace más de cuatro siglos: ${ }^{12}$ la producción de artefactos lingüísticos autónomos (lenguas y discursos propios) y la capacidad de sus artefactos para transformar las cosas y los cuerpos de los que se separan ("una revolución del mundo que los rodea según la ley del texto”). ${ }^{13}$

\footnotetext{
${ }^{9}$ No obstante, en lugar de situarse en una demostración plana y lineal, de Certeau privilegia lo que aún no se nombra y varía según las diversas escalas y capas de análisis. En este sentido, privilegiando los distintos modos (estratégicos) que dan acceso a los niveles infinitos del pasado, Michel de Certeau desestabiliza el carácter universal y totalizante de la historia. Se podría entonces yuxtaponer el análisis de tipo social, epistemológico, diacrónico, semiótico o psicoanalítico, considerándose aquello con lo que, según su diversificación, haría inviable pensar en un enfoque recapitulador, así que nada podría ocupar cualquier posición de dominio. Cfr. Dosse, Michel de Certeau, op. cit., p. 263.

10 "Estudioso y benévolo, tierno como soy con todos los muertos, signo mi camino, de edad en edad, siempre joven, nunca cansado, durante miles de ańos [...] Caminar y/o escribir, tal es el trabajo sin tregua 'impuesto por la fuerza del deseo, por el aguijón de una curiosidad ardiente a la que nada puede detener"'. Certeau, La escritura de la historia, op. cit., p. 14.

${ }^{11}$ Cfr. Certeau, La escritura de la historia, op. cit., pp. 203-227.

${ }^{12} \mathrm{Al}$ respecto conviene tener en cuenta el artículo de Alfonso Mendiola, "El conflicto moderno entre la voz y la escritura", publicado en el volumen 3 la revista Pelicano de 2017, dedicado al estudio de la obra de Michel de Certeau.

${ }^{13}$ Cfr. Certeau, La escritura de la historia, op. cit., p. 12.
} 
Jean de Léry, misionero calvinista que salió por primera vez de Ginebra en 1556 al encuentro con el pueblo tupinambá (o tupi) de la bahía de Río, en Brasil (la llamada "Francia Antártica"), dio lugar no sólo a una relación clave en la modernidad temprana, el "aquí" y el "allâ" en la cartografía (asociada a la cosmología) occidental, sino también aquello que en su relación de viaje ocasiona un descubrimiento esencial: el "Salvaje". Por medio del relato de Léry, Michel de Certeau señala que la etnología consiste en un recorrido circular en ambos lados de una división que se origina en las dicotomías estables entre el "mundo salvaje" y el "mundo civilizado", esto es, tal como Heródoto de Halicarnaso empleara a los escitas como figura de alteridad con el fin de argumentar el lugar correspondiente, por medio de la retórica, ${ }^{14}$ lo propio y lo extraño, "tomando distancia, una posición de intervalo a partir de la cual puede espacializar y disponer sus fuentes en su propia operación historiográfica". ${ }^{5}$ En el caso de Léry, la escritura aparece con todo su carácter expansionista, pero aun así, permanece atrapada en una doble reproducción del pasado y una conquista del espacio; asimismo, la oralidad se repliega en la misma insularidad que separa el "decir" y el "hacer": "lejos de la influencia de poderes, como una joya inalcanzable". ${ }^{16}$

Cuando el encuentro con el salvaje se produjo durante la colonización americana en el siglo xvI, hubo una fractura interna del discurso que "acaba por marcar la diferencia entre una faz de exte-

\footnotetext{
${ }^{14}$ En específico se trata de la figura retórica de la thôma, esto es, el relato de "algo extraordinario, una maravilla, esencial para una retórica de la alteridad: el relato de viajes", cuyo recurso germina de un encuentro con el otro para hacer verídico el relato, precisamente por ello tiene como fin persuadir: "producir un creer 'ordinario", a partir de un encuentro extraordinario. Cfr. Françoise Hartog, Le miroir d'Hérodote, pp. 243-249.

${ }^{15}$ Dosse, Michel de Certeau, op. cit., p. 513.

${ }^{16}$ Ibidem, p. 527.
} 
rioridad y de interioridad"; ${ }^{17}$ se trata de la bipolaridad originaria, pero peligrosa y escéptica (con verdades propias del "aquí" y desviaciones propias del "allá"), que es redistribuida por un esquema circular organizado a partir de un triángulo con tres referencias: el "aquî", ${ }^{18}$ que confronta como punto de partida y de regreso, la naturaleza extranjera del "allá” cuyas fronteras escindidas se dividen entre un "exotismo radical” y una "esperanza ética”, esto es, según el deseo (un querer escribir) y la expresión que le da Jean de Léry en su breviario al cuerpo por escribir. Teniendo en cuenta la formación calvinista de su personaje, Michel de Certeau lo caracteriza por sus interrogaciones sobre el indígena, hilando las cuatro nociones organizadoras de la etnología: "la oralidad (comunicación propia de la sociedad salvaje o primitiva, o tradicional), la espacialidad (cuadro sincrónico de un sistema sin historia, es decir, sin escritura), la alteridad (la diferencia que plantea una ruptura cultural), y la inconciencia (condición de fenómenos colectivos que se refieren a una significación que les es extrańa y que sólo se da a un saber venido de afuera)" ${ }^{19}$ Esa otredad, que confronta (altera) -o bien, este trabajo del otro en el interior de la nueva economía de la escritura occidental- "desemboca en una hermenéutica de la alteridad. Transporta al Nuevo Mundo el aparato exegético cristiano". ${ }^{20}$ Jean de Léry, de formación eminentemente protestante, realiza una hermenéutica que sustituye el lenguaje teológico -es decir, el propio cuando sale de Ginebra- y después es transformado en la práctica traductora de su punto de llegada. Michel de Certeau encuentra en Jean de Léry aquello que ya había analizado

\section{${ }^{17}$ Ibidem, p. 273.}

${ }^{18}$ El lugar originario o Ursprung, cuya etimología en alemán remite a la ciudad abrahámica de Ur de Caldea.

${ }^{19}$ Del mismo modo, en el estudio sobre Léry, Michel de Certeau observa que el cuadrilátero "etnológico" tiene su corolario en la historiografía moderna, "cuya construcción pone a trabajar, en la misma época, a cuatro nociones opuestas: la escritura, la temporalidad, la identidad y la consciencia". Certeau, La escritura de la historia, op. cit., p. 203.

${ }^{20}$ Ibidem, p. 231. 
en otros casos como el del padre Lebbe en China ${ }^{21}$ y que dibuja un horizonte transversal a su vida y su obra: la figura alterada por el otro del misionero, esto es, un viaje hacia el otro que se origina en la modernidad de un discurso que abandona sus lugares de origen (Ur), para pasar a ser un discurso científico con el fin de integrar al otro en su escritura y en su saber, a la manera en que el cristianismo ha debido marcar una desviación con respecto a la tradición judía.

La figura del salvaje es una efigie que restituye en su singularidad diversas errancias: ${ }^{22}$ formas extraordinarias y extraviadas para la unidad del saber y para el orden de las conductas. La figura del salvaje es situada en el espacio intermedio donde lo reprimido aflora a través de su relación con aquello que lo ha mantenido apartado. ${ }^{23}$ El salvaje rehabilita montículos de otro orden desaparecido. ${ }^{24}$ Integra todo aquello que emerge de un diálogo con una voz apenas incipiente, desaparecida o separada, esto es, el límite de una representación heterogénea que comienza donde se extravía lo otro del mundo. El salvaje se sitúa, para Michel de Certeau, en esa dinámica, en un punto intermedio, "en la historia que va del sujeto místico del siglo xvi al sujeto económico", 25 intervalo mediante el cual se puede rastrear el relato de una historia que entierra lo que se olvida: "[n]uestros queridos muertos entran en el texto porque no pueden ni dañarnos ni hablarnos. Los fantasmas se meten en la escritura, sólo cuando callan para siempre". ${ }^{26}$

Ahora bien, el salvaje es un actor ambiguo, se sitúa en el umbral entre el "aquî" y el "allá", constituye una suerte de figura de tránsito que aparece solamente para pasar; desvía y atraviesa otros órdenes. Sin embargo, no significa una amenaza, por lo que ad-

${ }^{21}$ Cfr. Michel de Certeau, "Un prophète: le Père Lebbe (1877-1940)".

${ }^{22}$ Dosse, Michel de Certeau, op. cit., p. 507.

${ }^{23}$ Idem.

${ }^{24}$ Idem.

${ }^{25}$ Certeau, La fábula mistica, p. 239.

${ }^{26}$ Ibidem, p. 16. 
quiere entonces un "valor de símbolo" en la medida que deja de organizar una fuerza amenazante, da testimonio de otro mundo; pero si lo arrestan y lo juzgan, es por delitos cometidos en éste. ${ }^{27}$ Las luchas de orden social y político no cruzan los espacios del salvaje, su mundo está condicionado por un vivir en un reformismo basado en un orden sociopolítico nuevo: "Pasa, y al pasar da testimonio del paso de lo uno a lo otro". ${ }^{28}$ Es el sumario de un caso extraordinario que esquiva la normalización de las conductas y de los métodos; en esa medida, es un trashumante, un nómada, cuyo espacio es un "espacio [en el] que se han distribuido iglesias establecidas o los estados salidos de la antigua cristiandad". ${ }^{29}$ Por eso, la modernidad, como lo ha indicado el profesor Alfonso Mendiola, consiste en un trabajo perpetuo por acceder a eso que perdió. ${ }^{30}$ La página en blanco, donde el salvaje se in-scribe, narra la trayectoria de un vagabundo que marca encuentros con aquello que aún resulta desconocido y funda lenguajes que transforman su espacio "en un campo de expansión para un sistema de producción". ${ }^{31}$ Así, la organización (etnográfica) de la escritura durante el siglo XVI, con relación a un tipo de oralidad salvaje, define y constituye su otro. Dicho de otra forma: reproduce el espejo de un movimiento que escapa a la mismidad del discurso, lo que para el caso del propio Michel de Certeau se traduce en un vivir la alteridad en la alteridad a-travesando espacios abyectos respecto de los sistemas de producción, circulación y saber. ${ }^{32}$ Esto se debe a que, de cierta manera, uno de los modos en que se da la fe jesuita implica caminar sin dirección fija más que hacia el otro. ${ }^{33} \mathrm{Y}$ esto ocurre a veces sin proponérselo, tal es el caso del encuentro

\footnotetext{
${ }^{27}$ Ibidem, p. 240.

${ }^{28}$ Idem.

${ }^{29}$ Idem.

${ }^{30}$ Mendiola, "El conflicto moderno", op. cit., 17.

${ }^{31}$ Certeau, La escritura de la historia, op. cit., p. 12.

${ }^{32}$ Cfr. Georges Vigarello, "Historia de cuerpos: entrevista Michel de Certeau".

${ }^{33}$ Dosse, Michel de Certeau, op. cit., p. 203.
} 
del personaje legendario de la obra de Certeau, Jean-Joseph Surin, quien establece una heterología con el joven del carruaje, "el iletrado ilustrado" hijo de un panadero del Havre en el siglo xvII quien le revela verdades extraordinarias. El encuentro transcurre entre el habla y la escucha (lo que remite a la fide ex auditu), pero también fuera del lugar común y originario.

En el caso de la Compañía de Jesús en el siglo xviI, en palabras de François Dosse, "ejército oficial del reformismo" en la coyuntura postridentina, sus experiencias con relación al cuerpo social (las reducciones de lugar, el exorcismo, la heterología, la ciencia mística de Jean Joseph Surin), enmarcadas en su mayoría en una salida permanente de sí hacia el otro, abrirán un encuentro organizado bajo los rasgos de una nueva espiritualidad cristiana. Por eso Jean de Labadie (alter ego de Certeau), un "profeta vagabundo para cuyo lenguaje ya no hay lugar", traza en su camino un recorrido compuesto de pequeñas historias de la mística, aquellas que, por aquel entonces, se resguardan en una clandestinidad efecto de una institucionalidad que inhuma sus huellas, pues el lenguaje que da lugar a la enunciación del otro que desplaza el "yo" que habla, se cifra en una época en la que se censuran los textos que antes circulaban sin fronteras y que pasaron a formar parte de una suerte de archivos secretos. ${ }^{34}$ Además de Labadie, en la Edad Media la figura del Idiotus en la obra de Nicolás de Cusa refunda los hechos de los primeros precursores de la Compañía, en medio del furor de una espiritualidad que contagia el noreste de Francia como si se tratara de "un doblete que finalmente falló y fue lanzado fuera de la herencia que dejaron los primeros padres". ${ }^{35}$ Ello conduce, pues, hacia "la figura central del 'hombre salvaje', invención nacida del ingenio de los siglos XIV y XV que se adelantó

${ }^{34} \mathrm{El}$ caso de los jóvenes celotes religiosos de Burdeos, o la trashumancia itinerante de Jean de Labadie desde Guyena hasta Dinamarca "en busca de una Iglesia". Para Certeau se trata de "novelas policiacas de la mística". Cfr. de Certeau, La fábula mistica, op. cit., p. 240.

${ }^{35}$ Idem. 
al descubrimiento Occidental de los 'salvajes' del Nuevo Mundo en el siglo XvI". ${ }^{36}$ La figura del "hombre salvaje" en el siglo XvI sentaría las bases de un discurso que antecede y organiza la experiencia de un "lenguaje que viene antes de lo que se dice". ${ }^{37}$

Ahora bien, la historia, como la etnología y, en el siglo xx, el psicoanálisis, ${ }^{38}$ "hace hablar al cuerpo que calla. Supone un desfasamiento entre la opacidad silenciosa de la 'realidad' que desea expresar y el lugar donde produce su discurso, protegida por la distancia que las separa de su objeto". ${ }^{39}$ Las "ciencias del otro", la historia, la etnología y el psicoanálisis, se conciben en lo fundamental como ciencias "del imposible eco de esa palabra no comunicable debido a la diferencia temporal y espacial"; la etnología, por ejemplo, queda "simplemente atrapada al vuelo del instante del viaje hacia la alteridad". ${ }^{40}$ Por eso, se interesará siempre por lo que no está escrito. ${ }^{41}$ En el caso de la historia, permanece atrapada "en una relación fundamentalmente ambivalente por la naturaleza de su escritura que remite al presente como una ficción que fabrica secretos y mentiras, al mismo tiempo que verdades". ${ }^{42}$ La escritura histórica pasa a ser performativa en el momento en que asume un papel

\footnotetext{
${ }^{36}$ Ibidem, p. 241.

${ }^{37}$ Idem.

${ }^{38}$ Michel de Certeau fue cofundador junto a Jacques Lacan, de la Escuela Freudiana de París en 1964 en el momento en que Lacan fue rechazado por la Asociación Psicoanalítica Internacional (IPA) y reunió algunos seguidores alrededor de la Escuela Francesa de Psicoanálisis en 1964, que pronto se convirtió en la Escuela Freudiana de París (EFP). En 1964 Lévi-Strauss dio la conferencia inaugural para explicitar la intención de "hacer brillar el psicoanálisis en otros campos del saber". Dosse, Michel de Certeau, op. cit., p. 164.

${ }^{39}$ Certeau, La escritura de la historia, op. cit., p. 35.

${ }^{40}$ Dosse, Michel de Certeau, op. cit., p. 528.

${ }^{41}$ Certeau, La escritura de la historia, op. cit., p. 204.

${ }^{42}$ Ibidem, p. 264.
} 
determinante en la construcción de un "sepulcro" para lo muerto, desempeńando así el papel de rito de entierro. De manera que la historiografía tendría una función simbólica que permita a una sociedad darse un pasado en el lenguaje. "La historia abre así al presente, un espacio propio: 'marcar' un pasado, es hacer un lugar a lo muerto, pero también volver a distribuir el espacio de los posibles". ${ }^{43} \mathrm{La}$ operación historiográfica se traduce en un "sepulcro" para lo muerto en un sentido doble: de honrarlo y eliminarlo. De este modo, la historia lleva a cabo un duelo.

Otro nivel correspondiente al papel performativo de la historia consiste en preguntarse ¿cómo darle lugar a una práctica de su situación autónoma con respecto a su otro, el pasado? ${ }^{24}$ De la función de "nuestro ser histórico", es decir, nuestra historicidad, Paul Ricoeur destaca en su libro La memoria, la historia, el olvido, la dimensión escriturística de la sepultura, a saber: el hecho de "enterrar los muertos que transforma en presencia interior la ausencia física del objeto perdido. La historia sería pues una forma de amplificación epistemológica de este acto de sepultura, el medio de salvar el "haber sido', del 'no ser ya". ${ }^{45} \mathrm{El}$ ausente de la historia, el "presente que falta" -y que de hecho da título a un célebre artículo de Michel de Certeau: L'absent de l'histoire-, es para siempre inaccesible, debido a que no se puede más que penetrar en el murmullo de la presencia que ha abandonado sus huellas. "Se fabrica una literatura a partir de huellas definitivamente mudas, lo que pasó ya no regresará y la voz se perdió para siempre". ${ }^{4}$ El ausente de la historia pierde en adelante su posición a través de la escritura de la historia, pero se convierte en la brecha que produce distancia, esto es, el discurso del otro. Ricoeur asume por su cuenta este análisis de la condición histórica en de Certeau, y

\footnotetext{
${ }^{43}$ Certeau, La escritura de la historia, op. cit., p. 118.

${ }^{44}$ Ibidem, p. 119.

${ }^{45}$ Dosse, Michel de Certeau, op. cit., p. 265.

${ }^{46}$ Michel de Certeau, L'absent de l'histoire. Repères sciences humaines et idéologies. Apud ibidem, p. 265.
} 
logra entrever en la construcción de este sepulcro, el paso de la "sepultura-lugar" a una "sepultura-acto" ${ }^{47}$ De este modo, la escritura hace entrar en la escena a una población de muertos ( $v$. gr. mentalidades, personajes, experiencias, etc.). La historiografía comienza donde se despide la voz. El historiador, llamado siempre a decir el otro, reproduce la formalidad de lo que se pierde sin remedio. En consecuencia, la operación historiográfica consistiría entonces en una manera contemporánea de practicar el duelo: se siguen los murmullos que, creyendo que se trata de una ciudad, conducen a lo que ahora es un mar. El cuerpo del testimonio reserva para sí aquello que no se puede revelar y, asimismo, da cuenta acaso de "algo de lo que construye [y tiene] el poder de hacernos partir". ${ }^{48}$

En la historia se halla la misma estructura de los cuadros unidos por una trayectoria, y que representa a los muertos a lo largo de un itinerario narrativo. Por eso, la práctica historiográfica fabrica un "efecto sobre lo real". Por ejemplo, la multiplicación de los nombres propios ( $v$. gr. personajes, experiencias, mentalidades, etc.) prolifera en el discurso histórico con los elementos "debajo de los cuales -dice Lévi-Strauss- lo único que se puede hacer es mostrar", ${ }^{49}$ y en los cuales el decir llega por necesidad a su límite, esto es, a lo más cercano al mostrar. La escritura sólo habla del pasado para enterrarlo; asimismo, la escritura tiene una función simbolizadora que permite a una sociedad situarse en un lugar al darse en el lenguaje un pasado, esto es, para abrir al presente un espacio: "marcar" un pasado es darle su lugar al muerto, pero también redistribuir el espacio de las posibilidades, "determinar negativamente lo que queda por hacer, y por consiguiente utilizar la narratividad que entierra a los muertos como medio de fijar un lugar a los vivos". 50

\footnotetext{
${ }^{47}$ Apud idem.

${ }^{48}$ Idem.

${ }^{49}$ A propósito de los nombres propios, cfr. Claude Lévi-Strauss, La Pensée sauvage, Plon, 1962, 285. Apud Certeau, La escritura de la historia, op. cit., p. 116.

${ }^{50}$ Certeau, La escritura de la historia, op. cit., p. 116.
} 
La escritura de la historia es una tumba con un doble sentido: honra y entierra con el mismo texto a sus muertos, pero aquí el lenguaje tiene por función introducir en el decir lo que ya no se hace. "Exorciza a la muerte y la sitúa en el relato que sustituye pedagógicamente algo que el lector debe creer y hacer". ${ }^{51}$ Ello se repite de múltiples formas, desde el cortejo fúnebre en la calle, hasta el entierro, pero por otra parte, de un modo diferente sucede con otras "tumbas" artísticas o sociales; la "reconducción del 'muerto' o del pasado a un lugar simbólico se articula aquí con el trabajo que tiene por fin crear en el presente un lugar (pasado o futuro) que debe llenarse, un 'deber' que hay que cumplir". ${ }^{52}$ Así libera al presente sin tener que nombrarlo, y así puede decirse que "hace muertos" para que en otra parte "haya vivos", o con más exactitud, recibe a los muertos producidos por un cambio social, con el fin de marcar el espacio abierto por ese pasado para que aún sea posible articular lo que aparece con lo que desaparece. El lenguaje habilita las prácticas para situarse con relación a su otro, el pasado, teniendo en cuenta que el lenguaje mismo es una práctica, de manera que la historiografía se sirve de la muerte para enunciar una ley (del presente) en el texto. Mediante su narratividad -por cuanto todo texto es discurso-, la escritura de la historia "proporciona a la muerte una representación, que al instalar la carencia en el lenguaje, fuera de la existencia, adquiere valor de exorcismo contra la angustia". ${ }^{33}$ En definitiva, la narratividad, o bien, la metáfora de una actuación, encuentra su soporte justo en lo que aparta, divide u oculta:

El otro es el fantasma de la historiografía, el objeto que busca, honra y entierra. Un trabajo de separación se efectúa en esta proximidad inquietante y fascinadora. Michelet se sitúa en las fronteras, donde desde Virgilio hasta Dante se han construido

\footnotetext{
${ }^{51}$ Ibidem, p. 117.

${ }^{52}$ Idem.

${ }^{53}$ Ibidem, p. 118.
} 
todas las ficciones que todavía no eran historia. Este lugar señala una cuestión ordenada desde entonces por prácticas científicas, y de la que se encarga ahora toda una disciplina: "la buisqueda histórica del 'sentido', no es sino la búsqueda del Otro", ${ }^{54}$ pero esta acción contradictoria trata de envolver y ocultar en el 'sentido' la alteridad de este extrańo, o, lo que es lo mismo, trata de calmar a los muertos que todavía se aparecen y ofrecerles tumbas escriturísticas. $^{55}$

Los muertos de los que se habla se convierten en el glosario de un trabajo que está por comenzar. Una ambivalencia de la historiografía: ella es la condición de un hacer y al mismo tiempo la negación de una ausencia; se porta como el discurso de una ley en el que el discurso histórico nos abre un presente que se debe realizar, sea como una coartada, una ilusión realista - "el efecto de lo real crea la ficción de otra historia"-, y, por otra parte, oscila permanentemente entre un "hacer historia" y "contar historias" sin que lo uno sea reductible a lo otro. "La escritura camina entre la blasfemia y la curiosidad, entre lo que elimina al construirlo como pasado y lo que organiza del presente, entre la privación o el desposeimiento que postula la normatividad social que impone al lector sin que él lo sepa" ${ }^{56}$ Por toda la suma de estos aspectos combinados en la "escenografía literaria", se simboliza el deseo que constituye la relación con el otro, es decir, la marca de la ley, por eso está en juego el destino de las posibilidades de una "ciencia objetiva", por cuanto nuestra relación con el lenguaje es siempre una relación con la falta, la ausencia y la muerte. En este sentido, el discurso histórico es la representación privilegiada de una "ciencia del sujeto - dice Jacques Lacan- tomado dentro de

\footnotetext{
${ }^{54}$ Alphonse Dupront, "Lenguaje e historia". XIII Congreso Internacional de Ciencias Históricas, Moscú, 1970. Apud ibidem, p. 16.

${ }^{55}$ Certeau, La escritura de la historia, op. cit., p. 16.

${ }^{56}$ Ibidem, p. 118.
} 
una división constituyente", ${ }^{57}$ pero esto es en el contexto de la escenografía de las relaciones que un cuerpo social mantiene con su lenguaje y las posibilidades que su tiempo hace posible.

IV

Resumiendo lo expuesto hasta el momento, la escritura histórica se traduce en la producción de un discurso, "una explicación" que se enuncia sobre una realidad que ha tenido lugar y que la escritura asigna como espacio de "producciones de lugar". ${ }^{58} \mathrm{La}$ relación que establece la historia entre la operación científica y la realidad que analiza, designa e interviene como discurso sobre el sentido de lo que ella esboza como "lo real". La disciplina histórica, entendida como la "fábrica de un discurso", se extiende ante todo sobre el horizonte que escribe al otro y lo real en un mismo texto. No obstante, Michel de Certeau sugiere, con concisión, que, más allá que el hecho de "implicar", "el lenguaje tiene como condición poner como otro distinto de él mismo, a la realidad de la que habla". ${ }^{99}$ En esta medida la historia contiene en sí misma una historicidad. La historicidad de la historia interviene de manera directa en el movimiento que enlaza la interpretación sobre una "praxis social". En consecuencia, Michel de Certeau sugiere un binomio que estriba entre una práctica que remite a una realidad, y a un "discurso cerrado" que consiste en ser un texto que "organiza y cierra un modo de inteligibilidad". ${ }^{60}$ Podríamos agregar, en este sentido, que la historia ejerce una suerte de "presión del lenguaje" que "obliga" al sentido a cambiar de acto a su resul-

${ }^{57}$ Jacques Lacan, Écrits, p. 859, "No existe una ciencia del hombre porque el hombre de la ciencia no existe, solamente existe su sujeto". Apud ibidem, p. 118. ${ }^{58}$ Certeau, La escritura de la historia, op. cit., p. 35.

${ }^{59} \mathrm{Idem}$.

${ }^{60} \mathrm{Idem}$. 
tado, "de lo activo del hacer a lo pasivo de ser visto, del gesto a su imagen en el espejo". ${ }^{61}$

La historia se nos aparece como mito. Articula "lo pensable" con los "orígenes" según un ser de lo social, comprende el margen de inteligibilidad que excede al discurso histórico. El caso de la relación entre psicoanálisis e historia, o teología e historia, por ejemplo, nos arroja con certeza a una pregunta por el hacer de la historia: la operación historiográfica enlaza distintas formas de relacionarse con las otras temporalidades, o bien, el sentido histórico frente a un conjunto de doctrinas que articulan "modos del decir". No obstante, en la medida en que hay un desplazamiento en el estudio de las ideas en el siglo xx -efecto de una rearticulación de las ideas frente a los problemas que surgen de las raíces de la noción de "hecho histórico"-, el hacer historiográfico toma el lugar del dato histórico, resignificando el papel de la investigación hacia otro exterior. En otras palabras: se pasa "de un sentido revelado por la realidad observada [...] al análisis de opciones o de organización de sentidos implicados por operaciones interpretativas". ${ }^{62}$

Ello podría sugerir que la historia renuncia a lo real para replegarse a su discurso a fin de examinar su hacer; no obstante, el sentido consiste en una reformulación de los términos que la historia sostiene con lo real (su trabajo radicaría entonces en reunir lo real y el discurso). Michel de Certeau otorga a la realidad (histórica) una dimensión que rebasa el discurso en la medida que el lenguaje entra a narrar hechos en virtud de la comunicación que nace de una heterología, esto es, un diálogo atravesado por el discurso, por cuanto el "hecho histórico" es producto de una "praxis" puramente social relativa a un acto que dialoga (habla y escucha) y establece la afirmación de un sentido específico.
${ }^{61}$ Idem.
${ }^{62}$ Idem.

La escritura ante el límite: lenguaje y narración en la operación... / 295 
La historia se funda en la ruptura de un pasado y un presente que se despliega en el horizonte de las prácticas pero siempre bajo las formas de un extrańamiento permanente por aquello que busca "e impone su ley a las regiones lejanas que conquista y cree darles la vida" ${ }^{63}$ La diferenciación de series, acontecimientos y periodos son la condición de interrelación entre las tropologías de la historia, para ponerlo en términos de Frank Ankersmit, quien sugiere que la historiografía ha funcionado como un substituto para la historia misma. ${ }^{64} \mathrm{La}$ tropología en Ankersmit, tal como sucede en la obra de Hayden White y gran parte de la crítica literaria de la segunda mitad del siglo xx -cuyos postulados lingüísticos pusieron en entredicho los acervos paradigmáticos más determinantes de las ciencias del hombre-, se deriva del esquema formalista de la obra histórica, esto es, poniendo de relieve el carácter deconstructivo de los marcos teórico-epistemológicos de los sistemas de producción historiográfica. ${ }^{65}$ Sin embargo, de Certeau, uno de los autores que ofrecieron una salida para el oficio de la historia en el marco del "giro lingüístico" junto con Hans Ulrich Gumbrecht, Reinhart Kosseleck o Frank Ankersmit, sugiere que hay un corte que define lo que la historia asume como límite original: un pasado. El tiempo pretérito es restituido por la operación historiográfica a modo de "resurrección" de la muerte. No obstante, esto es a pesar de la postulación de una desaparición aun cuando el "corte" definía un trabajo científico cuya objetividad se realizaba sobre lo que ya no tiene lugar: "[e]ste movimiento se debe precisamente al hecho de que el corte ha sido impuesto y no puede ser sostenido" ${ }^{66}$ La historia se despliega en las fron-

${ }^{63}$ Ibidem, p. 52.

${ }^{64}$ Cfr. F. R. Ankersmit, Historia y tropología: ascenso y caida de la metáfora; y Hayden White, El texto histórico como artefacto literario y otros escritos.

${ }^{65} \mathrm{El}$ enunciado histórico es entendido por Ankersmit (desde la historia) y White como un artefacto verbal que nace de los tropos principales de la retórica, a saber: la metáfora, la metonimia y la sinécdoque.

${ }^{66}$ Certeau, La escritura de la historia, op. cit., p. 53. 
teras donde la sociedad se relaciona con su pasado a través de la diferencia: "en las líneas que trazan la figura de una actualidad al separarla de su otro, pero que borran o modifican continuamente el retorno del 'pasado' [...] Hay vibración de límites. La relación que organiza la historia es una referencia cambiante en la que ninguno de los términos puede considerarse como estable". ${ }^{67}$

En definitiva, nos proponemos buscar los indicios que nos llevan a deducir que el pensamiento historiográfico de Michel de Certeau atraviesa de forma medular una heterología, cuyo elemento dialógico define un trabajo en los límites y el desplazamiento permanente de los centros: "Que pensar quiera decir pasar, exceso hacia el otro, éxtasis mortal de la identidad, tal es aquí el sentido del procedimiento". ${ }^{68}$ Se trata de una operación que tiene como principio aquello que se devela a través de una "arqueología de lo ausente", y que se difumina en el tiempo histórico bajo las reglas de la escritura del otro. "[E]sta situación fundamental se revela en nuestros días de muchas maneras que se refieren a la forma o al contenido de la historiografía" ${ }^{69}$ Para ello, es necesario poner el énfasis en un estado continuo de tensión, quizá el indicio clave en la investigación histórica donde el estudio se realiza sobre un método interpretativo con su "otro" o, con mayor precisión, "la evidencia de la relación que mantiene un modo de comprensión con lo incomprensible que 'ha hecho resaltar"” ${ }^{70} \mathrm{El}$ otro se revela para la operación histórica en los lugares donde la voz se despide (infans), cuyos lugares abyectos nos devuelven a las "regiones silenciosas de donde ha estado ausente": la brujería, el milagro, el salvaje, el místico, etc. "La razón científica está indisolublemente unida a la realidad que encuentra a su sombra y a su otro en el momento en que los excluye", esto

\footnotetext{
${ }^{67} \mathrm{Idem}$.

${ }^{68}$ Cfr. Michel de Certeau, "L'étrange secret. 'Manière d'écrire pascalienne".

${ }^{69}$ Certeau, La escritura de la historia, op. cit., p. 53.

${ }^{70}$ Ibidem, p. 54.
} 
es, de las técnicas de "diferenciación entre las ciencias". ${ }^{71}$ Por esta razón, se ha dicho que la escritura organiza lugares de pertenencia y lugares de ausencia, así es como a partir del siglo XVI se consolida un "sistema" en la escritura occidental que reviste una "conquista" de la oralidad -"salvaje", "primitiva", "tradicional", "popular"-. ${ }^{72}$

Michel de Certeau mostró que la problematización del sujeto va por fuerza de la mano con la especialización del cuerpo. Incluso, en el siglo xvi ya se tenía un "punto de focalización" de la problematización del sujeto y su relación con la experiencia filosófica, literaria y médica de la "melancolía", por ejemplo. En esa experiencia, el observador se separa de su mundo y sufre una privación que lo aleja de las cosas, aunque también goza con verlas apartadas. Esta relación aislaba al sujeto (extranjero del mundo) pero también al objeto, "hecho de cosas expuestas ante la mirada” ${ }^{73}$ Ésta es la mirada del ángel del grabado de la Melancholía I de Durero, cuya "separación instituye al sujeto como goce de ver lo que no tiene, pero también como deseo nacido de un desposeimiento. Este ojo del deseo hizo posible el cogito cartesiano". ${ }^{74}$ El melancólico enfrenta la diseminación indefinida de una "extensión" que es el léxico sin fin de las cosas. ${ }^{75}$ En esa misma época aparece la pasión enciclopédica de cotejar, enumerar y articular todas las cosas dispersas (reunir la continuidad entre las palabras y las cosas y recomponer la unidad universal de la lengua, etc.), como si el sujeto respondiera a la pérdida de la unidad de una "representación libresca" del mundo. "Una especie de cuerpo simbólico, un corpus sustituto del cosmos de antaño. Este trabajo no tiene fin porque proviene de un sujeto constituido por una pérdida y definido por un deseo que enajena sin que puedan sa-

\footnotetext{
${ }^{71}$ Idem.

${ }^{72}$ Ibidem, p. 12.

${ }^{73}$ Cfr. Vigarello, "Historia de cuerpos", op. cit.

${ }^{74}$ Idem.

${ }^{75}$ Idem.
} 
tisfacerlo cada uno de los objetos que toma. La pérdida de un cuerpo parece el motor de estas conquistas" ${ }^{76}$

Del mismo modo que el deseo melancólico nace del "desposeimiento" de un cuerpo y de la experiencia de ver el pasado que no se tiene, el historiador intenta reconciliar la separación entre lo real y el discurso, lo que también podría ponerse en términos de la voluntad historiográfica de dar cuerpo a su discurso. Por otra parte, el historiador debe hacer frente al desafío de captar la unidad de la verdad hasta su fondo, "el pasado" tal y como fue, pero, esta vez, en el plano de la "singularidad". A pesar de que lo real señala una rígida frontera entre uno y otro registro, siempre habrá complementariedad entre lo imaginario y lo real. Lo mismo podríamos decir del fundamento ficcional de la escritura histórica que de ninguna manera excluye lo real, sino que más bien lo solicita. La ficción ocurre en términos de producción del pasado, lo que constituye, para la modernidad, una relación ambigua, tanto de deuda como de rechazo. Asimismo, para identificar cómo funciona esta relación entre el pasado y la modernidad, debemos captar, también, la naturaleza de las relaciones que la historia mantiene con su "otro": lo real.

${ }^{76}$ En una dirección muy afín a la de de Certeau, Foucault sostuvo que la pregunta sobre cómo reconocer si un signo designa lo que significa, se tradujo en el siglo XviI en un análisis de la representación. Al mismo tiempo, para el pensamiento moderno se traduce en un análisis del sentido y de la significación. Para los clásicos, el lenguaje es solamente un caso particular de representación, así como para los "modernos" (e incluso estructuralistas) se trata de un problema de significación. Tanto para Michel de Certeau como para Michel Foucault, entre los siglos XV y XvII se deshace "la profunda pertenencia del lenguaje y del mundo" y a esto se refiere la expresión "cosmos de antaño". Después se termina con el primado de la escritura. En esos siglos "desaparece, pues, esta capa uniforme en la que se entrecruzaban indefinidamente lo visto y lo leído, lo visible y lo enunciable. Las palabras y las cosas van a separarse. El ojo será destinado a ver y sólo a ver; la oreja sólo a oír. El discurso tendrá desde luego como tarea decir lo que es, pero no será más que lo que dice”. Michel Foucault, Las palabras y las cosas: una arqueología de las ciencias humanas, p. 51. 
Todo esto se traduce en un trabajo alquímico de la historia: "transforma lo físico en social; toma prestado de lo físico para construir los modelos de lo social; produce imágenes de la sociedad con fragmentos de cuerpos". ${ }^{77}$ La pérdida de un cuerpo aparece como el "motor de sus conquistas", así como el Logos cristiano que se instaura a partir del "sepulcro vacío" y el "sitio vacío" para hacerse cargo de la producción de sus propios cuerpos; en consecuencia, la historia se convierte en una operación que comienza por la experiencia corporal de su autor, y por otro lado, desemboca en una relación con un eliminado, recupera los efectos en función de aquello que se le escapa, así como también establece permanencias aislando series y procurando métodos al distinguir los distintos objetos que se captan en un mismo hecho; por lo tanto, lo que se busca es comparar cronologías. ${ }^{78}$ Por esto decía Michel de Certeau, en un diálogo con Georges Vigarello y Olivier Mongin, que la historia procede a dar lugar a fabricaciones de cuerpos; el cuerpo -como categoría historiográfica si se quiereincluye mil variantes e improvisaciones en el interior del marco particular que de Certeau compara con un teatro de operaciones, cuyo conjunto es codificado para formar un cuerpo que, sin embargo, no se puede aprehender. Lo mismo sucede con la lengua: "uno capta realizaciones particulares que serían los equivalentes de frases o de estereotipos: comportamientos, acciones, ritos. Sin embargo, el campo de posibilidades y prohibiciones que el cuerpo constituye en cada sociedad es lo que no puede representarse". ${ }^{79}$

${ }^{77}$ Cfr. Vigarello, "Historia de cuerpos", op. cit.

${ }^{78}$ Por esta razón, Michel de Certeau prefiere hablar de límite y diferencia en lugar de discontinuidad, "término demasiado ambiguo porque parece postular la evidencia de un corte en la realidad". En la medida que no se trata de un corte en la realidad, pues el límite se "convierte en instrumento y objeto de investigación". Asimismo, de Certeau considera la diferencia como concepto operatorio de la práctica de escribir historiográficamente como dispositivo estratégico para poder rastrear el instrumento-fuente de investigación histórica.

${ }^{79}$ Cfr. Vigarello, "Historia de cuerpos", op. cit. 
En definitiva, para Michel de Certeau, "la historia no es una crítica epistemológica”, en la medida que siempre es relato, y remite a un proceso de escribir, "se comprende a sí misma en el conjunto y en la sucesión de producciones, de las cuales ella misma es un efecto". ${ }^{80}$ Asimismo, el fondo que traza de Certeau frente a la limitación tajante de las posibilidades que arguye el estructuralismo, ${ }^{81}$ se encuentra dentro de una estructura semántica que posibilita la combinación de distintos cuerpos (un cuerpo griego, un cuerpo indio, un cuerpo occidental moderno, etc.), que al igual que la "estructura atómica" su límite no es sino una "realización parcial". El cuerpo, como la historia, es algo mítico, en el sentido de que el mito es un discurso no experimental que autoriza y reglamenta unas prácticas, esto es, que lo que forma los cuerpos es una simbolización sociohistórica ( $v$. gr. hablar, persignarse, arrodillarse, orar, despedirse, lavarse, etc.). Michel de Certeau sostuvo que la historia moderna de la escritura (la que comienza en el siglo XvI) sería una variante de la historia que busca fabricar con el discurso diversos "cuerpos sociales", cuyas combinaciones permitirían "juegos de la diferencia", tal es el resultado de la "ida y vuelta" del viaje de Léry a Brasil: la invención del "Salvaje". ${ }^{82}$

El profesor Alfonso Mendiola ha señalado que la Voz irrumpe en la escritura como una fisura. "Todo fantasma que retorna se convierte en la Ley que constriñe a los vivos. Sólo esa fuerza de Ley de lo que se ha ido hace deseable (querer) el continuar tenazmente investigándolo a sabiendas que nunca lo podremos

${ }^{80}$ Certeau, La escritura de la historia, op. cit., p. 54.

${ }^{81}$ En una ponencia titulada "Estructuralismo e historia" dirigida a los miembros del grupo de historiadores de La Bussière en 1967, Michel de Certeau ponía de relieve, por primera vez, como un nuevo horizonte epistémico decisivo para el quehacer de los historiadores, la "fecundidad" pero también el problema del nuevo estatuto de la referencia del lenguaje que planteaba el estructuralismo.

${ }^{82}$ Certeau, La escritura de la historia, op. cit., p. 207. 
conocer". ${ }^{83}$ El otro que se va, como ha indicado el profesor Mendiola, "nos habita en forma de acto testamentaria: transmisión, tradición oral, etc. Algo o alguien que se ha ido nos donó la posibilidad de existir" ${ }^{84}$ Por esa razón, Michel de Certeau sostuvo que existe una fascinación provocada por el límite, que va unida al oficio tanto del etnólogo como del historiador, y ésta sería, en rigor, una "fascinación provocada por el otro" ${ }^{85}$ No obstante, el límite no radica en invocar en la escritura la voluntad de volver pensable una cosa. El discurso histórico interroga, en lo real, las limitaciones y las posibilidades que perfilan particularidades en los hechos; por lo tanto, el espacio del discurso remite a "una temporalidad diferente de la que organiza las significaciones según las reglas clasificatorias de la conjugación", ${ }^{86}$ esto es, el problema de la relación entre el discurso histórico y los lugares de enunciación, una relación entre coherencia y génesis. El origen (Ursprung), ${ }^{87}$ como

${ }^{83}$ Mendiola, "El conflicto moderno entre la voz y la escritura", op. cit., p. 17.

${ }^{84} \mathrm{Idem}$.

${ }^{85}$ Certeau, La escritura de la historia, op. cit., p. 60.

${ }^{86} \mathrm{Idem}$.

${ }^{87}$ Ursprung se refiere, en alemán, a la búsqueda del origen, cuya acepción genealógica en Nietzsche, a la luz de Foucault, se halla en relación a su vez con los términos Entstehung, Herkunf, Abkunft y Gebur. Sin embargo, en Nietzsche, la genealogía y la historia se perfila un rechazo a la búsqueda del origen; esta procura incesante, y acaso inevitable, consiste "en el esfuerzo por recoger allí la esencia exacta de la cosa, su más pura posibilidad, su identidad cuidadosamente replegada sobre sí misma, su forma móvil y anterior a todo aquello que es externo, accidental y sucesivo. Buscar un tal origen, es intentar encontrar 'lo que estaba ya dado', lo 'aquello mismo' de una imagen exactamente adecuada a sí: es tener por advertencias todas las peripecias que han podido tener lugar, todas las trampas y todos los disfraces [...] ¿si el genealogista se ocupa de escuchar la historia más que de alimentar la fe en la metafísica, qué es lo que aprende? [...]". Foucault señala a propósito de la genealogía de la historia en Nietzsche, que "el apego a la verdad y al rigor de los métodos científicos nacieron de la pasión de los sabios, de su odio recíproco, de sus discusiones fanáticas y siempre retomadas, de la necesidad de triunfar -armas lentamente forjadas a lo largo de luchas personales". Enclave que también está entrelazado con la búsqueda de la metafísica por un Wunderursprung como origen milagroso. Cfr. Michel Foucault, Nietzsche. La genealogía y la historia, p. 14. 
fórmula de la producción de sentido en el discurso histórico, tiene como principio una "actividad experimentada", resultado siempre de "acontecimientos" (viajes, trayectorias, desplazamientos), "estructuraciones", o bien, "la representación de una génesis organizadora que se le escapa". ${ }^{88}$

En conclusión, hemos visto cómo, en este sentido, Michel de Certeau mostraba en su estudio sobre Léry, cómo el discurso etnológico "quisiera decir lo que él construye al desterrar la oralidad fuera del campo ocupado por el trabajo occidental, convirtiendo así la palabra en un objeto exótico" ${ }^{89}$ Jean de Léry proporciona un punto de partida moderno, asegura una transición de la Historia, cuyo itinerario viaja a la "periferia del mundo" para traer de "alla’" un objeto literario (devuelto a la significación): el "salvaje" que permite volver al punto de partida. "El relato produce un retorno de uno mismo a uno mismo por la mediación del otro. Pero algo queda allá, que se le escapa al texto: la palabra tupi, que es del otro y no se puede recuperar - un acto perecedero que la escritura no puede relatar". ${ }^{90}$ Por ello, el elemento decisivo es la posesión o la privación de un instrumento (la escritura) capaz de "retener a las cosas en su pureza", el poder de retener el pasado "mientras que la 'fábula' salvaje está limitada al círculo evanescente de su audición, la escritura hace la historia [...] 'Declara', avanza 'hasta el fin del mundo"'. ${ }^{11}$

También se mostró cómo la historia (lo conocido y conservado, a diferencia de la voz) es el mito del lenguaje, bajo las formas del discurso, cuya escritura trata de probar que el lugar donde se produce es capaz de comprender el pasado; se trata del procedimiento discursivo que se niega a la pérdida, concediendo al presente el privilegio de recapitular el pasado en un saber. "Tra-

${ }^{88}$ Certeau, La escritura de la historia, op. cit., p. 60.

${ }^{89}$ Ibidem, p. 206.

${ }^{90}$ Ibidem, p. 206.

${ }^{91}$ Ibidem, p. 211.

La escritura ante el límite: lenguaje y narración en la operación... / 303 
bajo de la muerte y trabajo contra la muerte". ${ }^{92} \mathrm{Si}$ atendemos a ello en su sentido más radical, como lo vimos a lo largo de estas páginas, la historia se encarga de producir ausencias y olvidos; sin embargo, la operación historiográfica consiste en articular una relación con los muertos que "aspira a hacer hablar". Lo oral es "la forma presente del origen” y está en estrecha relación con lo que hay de mito en la historia, en la medida que, mediante la historia, "el lenguaje se ha enfrentado con su origen". ${ }^{33}$

El comienzo remite al "objeto perdido", la voz inaudible que se va, la falta que "tiene por función ser, entre los hombres, la representación de una escena primitiva borrosa pero todavía capaz de organizar".$^{94}$ Hablar de los muertos es siempre el decir de un vivo. Sin embargo, el ser de la muerte en la historia invoca un objeto de su saber, originando así un intercambio entre los vivos, diría de Certeau; a lo que podríamos agregar que hay un carácter afirmativo de la muerte que no designa un éskhatos o sus realidades póstumas, éskhata, sino que se trataría, en su lugar, de realidades pasadas que subvierten la idea de final, para designar más bien páreimi o "estar presente", una "asistencia" que denota presencia, pues lo póstumo no es alcanzado por la experiencia de lo final, sino mejor, del límite que traza continuidades a través de la palabra que contiene una ausencia. La negación del origen hace del lenguaje una huella que supervive de un comienzo "tan imposible de encontrar como de olvidar". 95 娄

${ }^{92}$ Ibidem, p. 19.

${ }^{93}$ Ibidem, p. 63.

94 "Mi análisis va y viene entre estas dos variantes de la misma relación estructural: los textos que estudia y los que produce [...] Por lo menos se manifiesta aquí una de las reglas del sistema que se ha constituido como 'occidental' y 'moderno': la operación escriturística que produce, preserva y cultiva 'verdades' imperecederas, se apoya sobre un rumor de palabras que se desvanecen tan pronto como se enuncian y por lo tanto, se pierden para siempre. Una 'pérdida' irreparable es la huella de dichas palabras en los textos que las buscaban. Así parece escribirse una relación encima de la otra”. Certeau, La escritura de la historia, op. cit., p. 206. ${ }^{95}$ Idem. 


\section{BibliografíA}

Ankersmit, F. R. Historia y tropología: ascenso y caida de la metáfora, México, Fondo de Cultura Económica, 2004 (Breviarios, 516).

Barthes, Roland. "El discurso de la historia", Social Science Information, vI, 4, 1967, pp. 65-75.

Certeau, Michel de. L'absent de l'histoire, París, Mame, 1973 (Repères sciences humaines et ideologies).

- "L'étrange secret. 'Manière d'écrire pascalienne", Rivista di storia e letteratura religiosa, t. 13, 1977, pp 104-126.

-. La debilidad de creer, Buenos Aires, Katz Editores, 2006.

- La escritura de la historia, México, Universidad Iberoamericana, 1993 (El Oficio de la Historia).

- La fábula mistica: siglos XVI-XVII, México, Universidad Iberoamericana, 1993 (El Oficio de la Historia).

. La invención de lo cotidiano: artes de hacer, t. I, México, Universidad Iberoamericana, 1996 (El Oficio de la Historia).

. "Un prophète: le Père Lebbe (1877-1940)", Bulletin Saint Jean-Baptiste, t. VI-2, diciembre de 1965, pp. 81-91.

Dosse, François. Michel de Certeau. El caminante herido, México, Universidad Iberoamericana, 2003 (El Oficio de la Historia).

Fabre, Pierre Antoine. "La cuestión mística en la posteridad de Michel de Certeau", Pelícano. Revista de la Facultad de Filosofía y Humanidades de la Universidad Católica de Córdoba, vol. 3, 2017, pp. 5-15.

Foucault, Michel. Las palabras y las cosas: una arqueologia de las ciencias humanas, México, Siglo xxi, 1997.

Nietzsche. La genealogía y la historia, Madrid, Pre-Textos, 2000.

Freijomil, Andrés Gabriel. “El nuevo mundo como 'página en blanco’. Elementos para una historia de las representaciones de América Latina en la obra de Michel de Certeau", Pelícano. Revista de la Facultad de Filosofía y Humanidades de la Universidad Católica de Córdoba, vol. 3, 2017, pp. 31-38.

"La historia como alegoría de la fábula de Michel de Certeau", Thélème. Revista Complutense de Estudios Franceses, núm. 23, 2008, pp. 53-66.

Hartog, Françoise. Le miroir d'Hérodote, París, Gallimard, 1980.

Lacan, Jacques. Écrits, París, Seuil, 1966.

La escritura ante el límite: lenguaje y narración en la operación... / 305 
Mendiola, Alfonso. "El conflicto moderno entre la voz y la escritura", Pelícano. Revista de la Facultad de Filosofia y Humanidades de la Universidad Católica de Córdoba, vol. 3. 2017, pp. 16-30.

- "El conflicto o la unión en la diferencia: Institución, creencia y herejía en Michel de Certeau”, Historia y Grafía, núm. 30, 2008, pp. 37-64.

- "El giro historiográfico: La observación de observaciones del pasado", Historia y Grafía, núm. 15, 2000, pp. 181-208.

- "Historizar la teología y los dogmas de la Iglesia: el compromiso de Michel de Certeau”, Historia y Grafía, núm. 38, 2012, pp. 173-207.

- Michel de Certeau. Epistemología, erótica y duelo, México Ediciones Navarra, 2014.

Tozzi, Verónica. "Introducción", en Hayden White, El texto histórico como artefacto literario y otros escritos, Barcelona, Editorial Paidós, 2003 (Pensamiento Contemporáneo, 71).

Urrejola, Bernarda. "Entre mística e historiografía: el lenguaje de la ausencia en Michel de Certeau", Historia y Grafía, núm. 35, 2010, pp. 151-181.

Vigarello, Georges. "Historia de cuerpos: entrevista Michel de Certeau", Historia y Grafía, 1997, núm. 9, pp. 11-18.

White, Hayden. El texto histórico como artefacto literario y otros escritos, Barcelona, Editorial Paidós, 2003 (Pensamiento Contemporáneo, 71). 